\title{
Ozonolysis of surface-adsorbed methoxyphenols: kinetics of aromatic ring cleavage vs. alkene side-chain oxidation
}

\author{
E. M. O'Neill, A. Z. Kawam, D. A. Van Ry, and R. Z. Hinrichs \\ Department of Chemistry, Drew University, Madison, New Jersey, USA
}

Correspondence to: R. Z. Hinrichs (rhinrich@drew.edu)

Received: 11 July 2013 - Published in Atmos. Chem. Phys. Discuss.: 29 July 2013

Revised: 7 November 2013 - Accepted: 18 November 2013 - Published: 2 January 2014

\begin{abstract}
Lignin pyrolysis products, which include a variety of substituted methoxyphenols, constitute a major component of organics released by biomass combustion, and may play a central role in the formation of atmospheric brown carbon. Understanding the atmospheric fate of these compounds upon exposure to trace gases is therefore critical to predicting the chemical and physical properties of biomass burning aerosol. We used diffuse reflectance infrared spectroscopy to monitor the heterogeneous ozonolysis of 4propylguaiacol, eugenol, and isoeugenol adsorbed on $\mathrm{NaCl}$ and $\alpha-\mathrm{Al}_{2} \mathrm{O}_{3}$ substrates. Adsorption of gaseous methoxyphenols onto these substrates produced near-monolayer surface concentrations of $3 \times 10^{18}$ molecules $\mathrm{m}^{-2}$. The subsequent dark heterogeneous ozonolysis of adsorbed 4-propylguaiacol cleaved the aromatic ring between the methoxy and phenol groups with the product conclusively identified by GC-MS and ${ }^{1} \mathrm{H}-\mathrm{NMR}$. Kinetic analysis of eugenol and isoeugenol dark ozonolysis also suggested the formation of ring-cleaved products, although ozonolysis of the unsaturated substituent groups forming carboxylic acids and aldehydes was an order of magnitude faster. Average uptake coefficients for $\mathrm{NaCl}$ adsorbed methoxyphenols were $\gamma=2.3( \pm 0.8) \times 10^{-7}$ and $2( \pm 1) \times 10^{-6}$ for ozonolysis of the aromatic ring and the unsaturated side chain, respectively, and reactions on $\alpha$ $\mathrm{Al}_{2} \mathrm{O}_{3}$ were approximately two times slower. UV-visible radiation $(\lambda>300 \mathrm{~nm})$ enhanced eugenol ozonolysis of the aromatic ring by a factor of $4( \pm 1)$ but had no effect on ozonolysis of the alkene side chain.
\end{abstract}

\section{Introduction}

Combustion of biomaterials - including natural and anthropogenic forest and grass fires as well as domestic burn- ing for heating and cooking - represents a major tropospheric source of organic and carbonaceous particulates (e.g., Crutzen and Andreae, 1990; Seiler and Crutzen, 1980; Kasischke and Penner, 2004). Microscopic analysis of biomass burning aerosol reveals complex and diverse chemical composition and structure, including soot, tar balls, internally mixed organic-potassium salt particles, and mineral dust containing organic coatings (Posfai et al., 2003; Li et al., 2003, 2010). Volatile and semivolatile organic compounds (VOC and SVOC) are also emitted by biomass burning and may adsorb onto extant airborne particles, further contributing to the organic composition of tropospheric aerosols (Falkovich and Rudich, 2001). The chemical speciation of biomass aerosols and accompanying SVOCs depend on fuel source (e.g., grasses, softwood and hardwood species) as well as combustion conditions (Kjallstrand et al., 1998; Oros and Simoneit, 2001a, b; Reid et al., 2005; Janhall et al., 2010; Zhang et al., 2013).

Lignin is a structural biological polymer synthesized from monolignols (paracoumaryl alcohol, coniferyl alcohol, and sinapyl alcohol) accounting for $25-35 \%$ of the dry mass of softwood species and 18-25\% of hardwoods (Wool and Sun, 2005). Thus, lignin pyrolysis products constitute major emissions from forest fires and residential heating based on wood combustion. Field studies have detected an array of lignin pyrolysis products in ambient air, especially in urban areas with significant residential wood heating (Hawthorne et al., 1989, 1992; Nolte et al., 2001; Bari et al., 2009) and downwind of forest fires (Hoffer et al., 2006). Shakya et al. (2011) also detected lignin polymers in Houston aerosols attributed to directly emitted biological aerosols, which have estimated annual emissions of $50 \mathrm{Tg}$ (Kiehl and Rodhe, 1995). Field and laboratory measurements suggest that lignin pyrolysis 


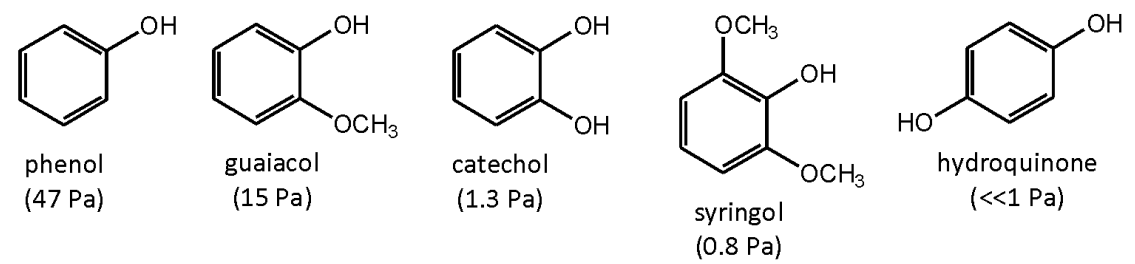

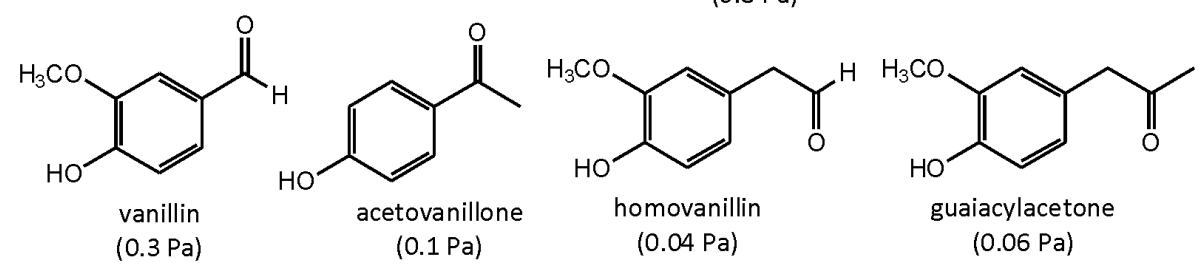
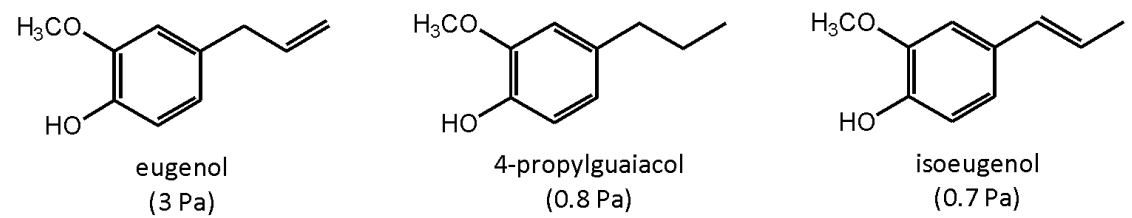

Fig. 1. Prevalent lignin pyrolysis products with vapor pressures listed in parentheses.

products undergo relatively efficient photooxidation (Hoffer et al., 2006), the products of which may contribute to atmospheric humic-like substances (HULIS) (Gelencser et al., 2003; Hoffer et al., 2004); the extent and mechanisms of this chemistry, however, remain uncertain. Important daytime reactions could include $\mathrm{OH}$-initiated chemistry, ozonolysis, and photoenhanced oxidation.

Dozens of compounds classified as lignin pyrolysis products have been identified in biomass burning emissions (Oros and Simoneit, 2001a, b; Schauer et al., 2001). Given the structures of the monolignols that comprise lignin, it is not surprising that phenols, methoxyphenols, and dimethoxyphenols are prevalent motifs in lignin pyrolysis products. Figure 1 displays 12 lignin pyrolysis products along with their vapor pressures, listed in parentheses, which fall in the range of semivolatile compounds. Catechol and guaiacol are of particular interest because the ozonolysis of these compounds results in efficient secondary organic aerosol (SOA) formation (Coeur-Tourneur et al., 2009, 2010; Ofner et al., 2010, 2011). For these systems, ring-cleaved products, which have lower volatility as a result of additional polar functional groups, contributed to SOA growth and likely play a role in SOA nucleation.

Several recent studies have focused on heterogeneous reactions of surface-adsorbed methoxyphenols with $\mathrm{O}_{3}$ and/or $\mathrm{NO}_{3}$ (Knopf et al., 2011; Net et al., 2010a, b, 2011; Liu et al., 2012). For instance, Net et al. (2011) investigated the heterogeneous ozonolysis of several methoxyphenols adsorbed on silica. Many methoxyphenols (i.e., vanillic acid, syringic acid, acetovanillone, and acetosyringone) did not react; two aldehydes (vanillin and syringaldehyde) were oxidized to carboxylic acids, while only coniferyl alcohol, the only methoxyphenol studied containing an alkene side group, reacted via a 1,3-cycloaddition mechanism. No ring-cleaved products were observed. In a separate study, ozonolysis of silica-adsorbed coniferyl aldehyde produced glycolic acid, oxalic acid, vanillin, vanillic acid, and 3,4-dihydroxybenzoic acid (Net et al., 2010a). Knopf et al. (2011) measured a reactive uptake coefficient of $\gamma=8.3 \times 10^{-5}$ for $\mathrm{O}_{3}$ on thin film nitroguaiacol, which was more reactive than levoglucosan and abietic acid; reaction products were not identified in this study.

Here we evaluate the relative importance of ozone 1,3cycloaddition to alkene side chains vs. across methoxyphenols by identifying products and measuring reaction kinetics for the heterogeneous ozonolysis of eugenol, isoeugenol, and 4-propylguaiacol (Fig. 1 bottom row). Given the semivolatile vapor pressures of these compounds, the current experimental samples were prepared by adsorbing gaseous methoxyphenols onto inorganic tropospheric aerosol substrates that represent biogenic salt and mineral dust aerosol present in biomass burning emissions. This builds on our prior work investigating the heterogeneous ozonolysis of $\mathrm{NaCl}$ - and $\alpha-\mathrm{Al}_{2} \mathrm{O}_{3}$-adsorbed catechol (Woodill et al., 2013). Infrared spectroscopy, gas chromatographymass spectroscopy, and nuclear magnetic resonance spectroscopy are combined to address the following question: how prevalent are ring-cleaved products? To evaluate the kinetics of these systems under atmospheric conditions, the impact of relative humidity and solar radiation on the ozonolysis of eugenol was also investigated. 


\section{Methods}

\subsection{Infrared spectroscopy}

We used infrared spectroscopy to characterize gaseous and surface-adsorbed methoxyphenols. Eugenol, isoeugenol, and 4-propylguaiacol (Aldrich, $98 \%$ ), which all have vapor pressures ca. $1 \mathrm{~Pa}$, were used without further purification. A continuous flow of dry, purified air bubbled through liquid methoxyphenols entraining these semivolatile organic compounds in the gas phase. Gas phase spectra were recorded by directing this flow through a $2 \mathrm{~L}$ transmission gas cell, which uses White cell optics to achieve a $10 \mathrm{~m}$ pathlength (Thermo Antaris), housed in a Thermo Nicolet 6700 FTIR equipped with an MCT-A detector.

Diffuse reflectance (DRIFTS) and attenuated total reflectance infrared spectroscopy (ATR-FTIR) monitored the adsorption of gaseous methoxyphenols on $\mathrm{NaCl}$ or $\alpha-\mathrm{Al}_{2} \mathrm{O}_{3}$ substrates and the subsequent heterogeneous ozonolysis of these samples. Ball-milled $\mathrm{NaCl}$ (Aldrich, 99.999\%) had a surface area of $0.12 \mathrm{~m}^{2} \mathrm{~g}^{-1} ; \alpha-\mathrm{Al}_{2} \mathrm{O}_{3}$ (Alfa Aesar, 99.98\%) was used without ball milling and had a surface area of $14 \mathrm{~m}^{2} \mathrm{~g}^{-1}$. For DRIFTS, inorganic powders were packed into a reaction chamber (Harrick Scientific, Praying Mantis) and heated to $300^{\circ} \mathrm{C}$ under the continuous flow of dry air for at least $60 \mathrm{~min}$. After cooling to $25^{\circ} \mathrm{C}$, a background spectrum was recorded at $4 \mathrm{~cm}^{-1}$ resolution averaging 256 scans. For ATR-FTIR, a methanol $/ \alpha-\mathrm{Al}_{2} \mathrm{O}_{3}$ slurry was evenly spread over the ZnSe ATR crystal, which was then placed in an oven at $100{ }^{\circ} \mathrm{C}$ for $90 \mathrm{~min}$ to remove all methanol. We then attached the ATR flow cell (Pike Technologies, HATR) to the continuous flow manifold and recorded a background after purging the system for $60 \mathrm{~min}$.

The relative humidity $(\mathrm{RH})$ was controlled by adjusting the relative flow rates of dry and wet streams of purified air using two mass flow controllers. RH was measured upstream of the DRIFTS reaction chamber using a Vaisala HMT338 gauge. It should be noted that even under "dry" conditions (referred to as $0 \%$ hereafter) the DRIFTS substrates contain residual surface-adsorbed water (Goshal et al., 2004). The dry flow could be diverted through the organic bubbler, thereby exposing the $\mathrm{NaCl}$ or $\alpha-\mathrm{Al}_{2} \mathrm{O}_{3}$ substrates to gaseous methoxyphenols. Spectra recorded continuously with an approximate averaging time of three minutes monitored adsorption of gaseous methoxyphenols, and saturated surface coverage was typically achieved in $90 \mathrm{~min}$ or less. After isolating the methoxyphenol bubbler, coated samples were purged with air for a minimum of $30 \mathrm{~min}$ with negligible loss of adsorbed organics. Heterogeneous ozonolysis was then investigated using a photolytic ozone generator in the dry air stream, which was connected to the reaction chamber by a polypropylene tube to remove any $\mathrm{OH}$ radicals (Woodill et al., 2013). Ozone concentrations were constant during the course of each experiment, and separate experiments were conducted with concentrations ranging from
$4 \times 10^{12}$ to $25 \times 10^{12}$ molecules $\mathrm{cm}^{-3}$ (150 to 990 parts per billion - ppb) as measured by a Jelight 308 ozone monitor. The majority of reactions were conducted under dark conditions; however, a series of eugenol ozonolysis experiments used a xenon lamp solar simulator to test for photoenhanced chemistry. Infrared and UV $(\lambda<300 \mathrm{~nm})$ radiation was filtered out of the xenon lamp output using water and borosilicate filters, respectively. The solar simulator spectral irradiance (Supplement, Fig. S1) was determined by correlating the integrated power $(\lambda<800 \mathrm{~nm})$, measured with a Newport Oriel power meter, and the relative intensity as a function of wavelength, which was measured using an Ocean Optics spectrometer (HR2000). Diffuse reflectance UV-visible spectra of adsorbed organics were recorded in a similar manner as described for DRIFTS using a Thermo Evolution 300 spectrometer.

Quantum chemical calculations of eugenol, isoeugenol, and 4-propylguaiacol identified vibrational normal modes associated with infrared peaks. All calculations were performed using Gaussian 09 (Frisch et al., 2009). Ground-state minima were optimized at the B3LYP/6-31G(d,p) level of theory, and harmonic frequency calculations were scaled by 0.977 to account for neglected anharmonic terms, which allowed for comparison to experimental spectra (Irikura et al., 2005).

\subsection{Extraction and analysis of adsorbed organics}

To determine adsorbed organic surface concentrations, methoxyphenols were extracted from $\mathrm{NaCl}$ DRIFTS samples in $2-3 \mathrm{~mL}$ of acetonitrile. $\left(\alpha-\mathrm{Al}_{2} \mathrm{O}_{3}\right.$ samples were not extracted due to the monodentate binding of methoxyphenols, discussed below.) Extracted slurries were sonicated for $60 \mathrm{~min}$ then filtered using a $0.2 \mu \mathrm{m}$ syringe filter. Many samples were derivatized with N,O-bis(trimethylsilyl)trifluoroacetamide (BSTFA, Fluka 99\%) to reduce polarity by silating hydroxyl and carboxylic acid groups. Extracted organics were analyzed on an Agilent Technologies GC-MS (6890N-GC/5973-MS) with a Supelco SLB-5ms column and the $\mathrm{GC}$ oven temperature ramped from 70 to $200^{\circ} \mathrm{C}$.

To analyze reaction products using GC-MS and ${ }^{1} \mathrm{H}-\mathrm{NMR}$, $\sim 1 \mathrm{~g}$ samples of $\mathrm{NaCl}$ were packed into a fritted glass stem attached to a gas manifold. Adsorption of methoxyphenols and their subsequent ozonolysis was executed in a manner similar to that discussed above, except coating and reaction times were increased tenfold. For GC-MS, organics were extracted and sonicated in acetonitrile, filtered, and then derivatized using BSTFA. For NMR, reacted samples were extracted using deuterated acetone (Aldrich, 99\%, $0.03 \%$ TMS) and then analyzed without filtering using a $200 \mathrm{MHz}$ Bruker NMR, averaging 30000 scans. 


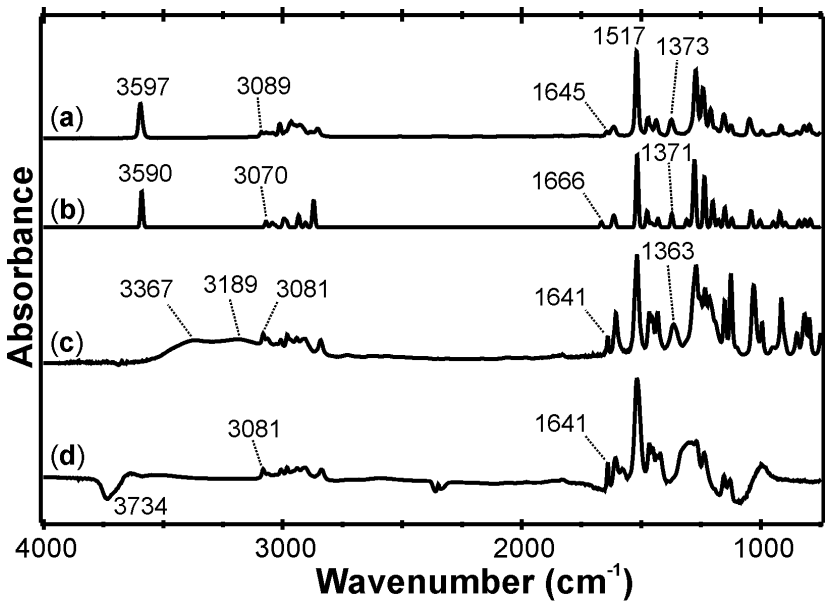

Fig. 2. (a) Experimental and (b) computational spectra of gaseous eugenol. DRIFTS spectra of eugenol adsorbed on (c) $\mathrm{NaCl}$ and (d) $\alpha-\mathrm{Al}_{2} \mathrm{O}_{3}$.

\section{Results and discussion}

\subsection{Adsorption of methoxyphenols on $\mathrm{NaCl}$ and $\alpha$ - $\mathrm{Al}_{2} \mathrm{O}_{3}$}

Comparing experimental and computational spectra of gaseous methoxyphenols facilitates the assignment of vibrational normal modes to the observed infrared peaks (Table 1). Optimization and frequency calculations at the B3LYP/6$31 \mathrm{G}(\mathrm{d}, \mathrm{p})$ predicted harmonic vibrational frequencies, which were scaled by 0.977 to account for neglected anharmonic terms, and infrared intensities. Figure 2 displays the excellent agreement between the (a) experimental and (b) computational spectra of gaseous eugenol. Notable vibrational modes relevant to the ensuing discussion include phenol $(\mathrm{OH})$ stretching and bending vibrations at 3597 and $1373 \mathrm{~cm}^{-1}$, alkene side-chain $\mathrm{CH}$ and $\mathrm{C}=\mathrm{C}$ stretching vibrations at 3089 and $1645 \mathrm{~cm}^{-1}$, and an intense aromatic ring vibration centered at $1517 \mathrm{~cm}^{-1}$. Excellent agreement was also observed for isoeugenol and 4-propylguaiacol.

Figure 2 also shows DRIFTS spectra for eugenol adsorbed on (c) $\mathrm{NaCl}$ and (d) $\alpha-\mathrm{Al}_{2} \mathrm{O}_{3}$. NaCl-adsorbed eugenol retained most of the spectral features seen for gaseous eugenol with only minor frequency shifts. The most notable difference was the broadened phenol $\mathrm{OH}$ stretching vibration, which exhibited two peaks centered at 3189 and $3367 \mathrm{~cm}^{-1}$. The phenol bending vibration at $1363 \mathrm{~cm}^{-1}$ also displayed significant broadening. These features indicate that eugenol physisorbed to the $\mathrm{NaCl}$ surface, similar to the adsorption of catechol on $\mathrm{NaCl}$ (Woodill et al., 2013). Based on this comparison, we infer that a dominant binding interaction on the $\mathrm{NaCl}(001)$ surface involves donation of an electron lone pair on the methoxy oxygen atom to $\mathrm{a} \mathrm{Na}^{+}$cation and an interaction analogous to a weak hydrogen bond from the phenol to an adjacent $\mathrm{Cl}^{-}$anion (e.g., Reaction Scheme (R1)). Defect and edge sites, which are prevalent in the employed powder samples, also provide favorable binding sites.
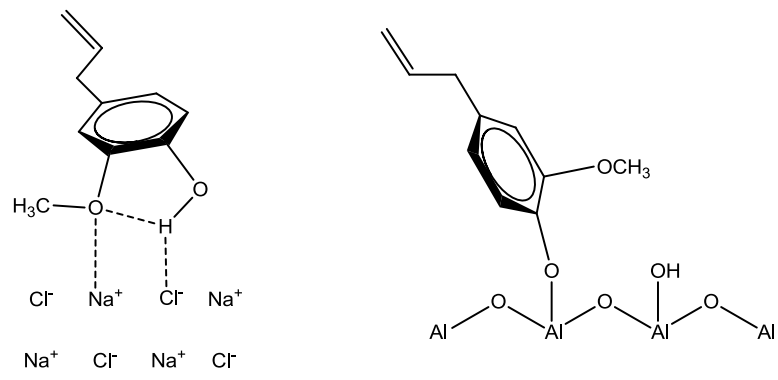

$\alpha-\mathrm{Al}_{2} \mathrm{O}_{3}$ adsorbed eugenol exhibits features consistent with monodentate binding: absent phenol stretching and bending vibrations, and a negative peak at $3734 \mathrm{~cm}^{-1}$ associated with the loss of alumina surface hydroxyl groups upon eugenol adsorption. Our previous work noted analogous binding for catechol on $\alpha-\mathrm{Al}_{2} \mathrm{O}_{3}$, which was identified as binuclear bidentate catecholate (Woodill et al., 2013). As characterized in Reaction Scheme (R1), the alkene side chain likely dangles off each organic-coated substrate, and vibrational frequencies associated with this group were within $8 \mathrm{~cm}^{-1}$ of gaseous eugenol modes. Isoeugenol and 4-propylguaiacol spectra also indicated physisorption on $\mathrm{NaCl}$ and monodentate complexes on $\alpha-\mathrm{Al}_{2} \mathrm{O}_{3}$.

A powerful aspect of DRIFTS is that the samples are large enough $(\sim 100 \mathrm{mg}$ inorganic substrates $)$ that the adsorbed organics may be solvent extracted for analysis by GC-MS, allowing for identification and quantification by comparison to standards. Several $\mathrm{NaCl}$ DRIFTS samples were sonicated in acetonitrile for $60 \mathrm{~min}$, filtered, and then derivatized with BSTFA for GC-MS analysis. Comparison to eugenol standards quantified the extracted concentration, which combined with the BET surface area determined the $\mathrm{NaCl}$-adsorbed eugenol concentration to be $3( \pm 1) \times 10^{18}$ molecules $\mathrm{m}^{-2}$. This value is similar to the $3.5 \times 10^{18}$ molecules $^{-2}$ surface concentration measured for catechol adsorbed on $\mathrm{NaCl}$ (Woodill et al., 2013) and is consistent with the similar physisorption binding proposed above. Since it is difficult to estimate the effective area of an individual adsorbed methoxyphenol, we cannot accurately calculate the fraction of a monolayer. Nonetheless, based on our prior work with surface-adsorbed catechol, we believe these surface concentrations correspond to near monolayers (Woodill et al., 2013). For $\alpha-\mathrm{Al}_{2} \mathrm{O}_{3}$, the magnitude of the negative surface hydroxyl peak at $3734 \mathrm{~cm}^{-1}$ can be compared to the maximum loss of this signal at high humidity (Woodill et al., 2013), implying a surface concentration of $3( \pm 2) \times 10^{18}$ molecules $^{-2}$. We expect all methoxyphenols studied here to have similar near-monolayer surface concentrations for both $\mathrm{NaCl}$ and $\alpha-\mathrm{Al}_{2} \mathrm{O}_{3}$ substrates. 
Table 1. Vibrational assignments $\left(\mathrm{cm}^{-1}\right)$ for eugenol and its ozonolysis products.

\begin{tabular}{lcccccc}
\hline & \multicolumn{3}{c}{ Eugenol } & & \multicolumn{2}{c}{ Ozonolysis products } \\
\cline { 2 - 3 } \cline { 6 - 7 } Normal mode & Gaseous & $\mathrm{NaCl}$ & $\alpha-\mathrm{Al}_{2} \mathrm{O}_{3}$ & & $\mathrm{NaCl}$ & $\alpha-\mathrm{Al}_{2} \mathrm{O}_{3}$ \\
\hline Al-O-H, surface hydroxyl & & & $3734^{*}$ & & $3734^{*}$ \\
Phenol OH stretch & 3597 & 3189,3367 & - & & \\
Alkene CH stretch & 3089 & 3081 & 3081 & & \\
Aromatic CH stretch & 3013 & 3009 & 3009 & & 1736 & 1726 \\
Carbonyl C=O stretch & & & & & & 1620 \\
Carboxylate stretch & & & & & \\
Alkene C=C stretch & 1645 & 1641 & 1641 & & \\
Aromatic ring stretch & 1517 & 1518 & 1518 & & \\
Methoxy CH bend & 1471 & 1466 & 1466 & & \\
Methoxy/aromatic CH bend & 1439 & 1431 & 1435 & & \\
Phenol OH bend & 1373 & 1363 & - & & \\
Aromatic ring breathing & 1273 & 1269 & v. broad & & \\
\hline
\end{tabular}

* Negative peaks indicating loss of surface hydroxyl group upon eugenol adsorption.

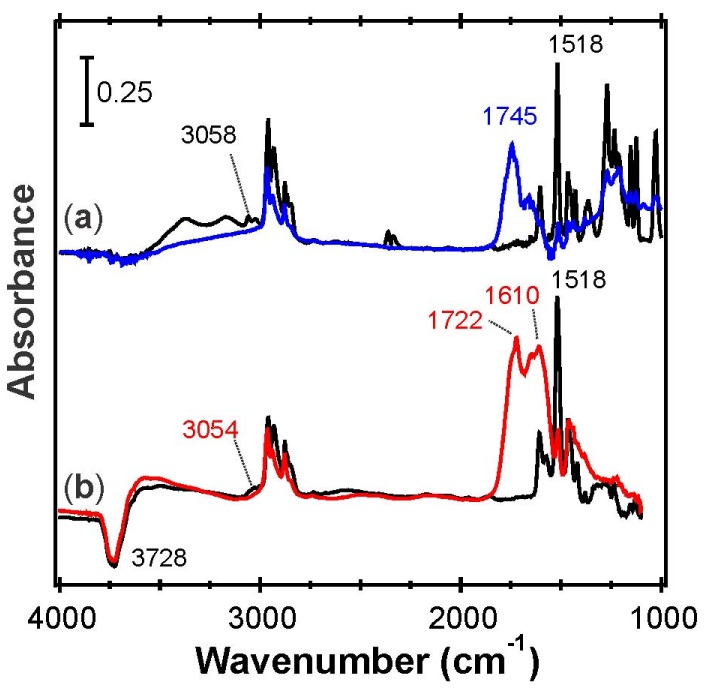

Fig. 3. DRIFTS spectra of 4-propylguaiacol adsorbed on (a) $\mathrm{NaCl}$ exposed to $551 \mathrm{ppb} \mathrm{O}_{3}$ at $t=0 \mathrm{~min}$ (black) and $500 \mathrm{~min}$ (blue), and (b) $\alpha-\mathrm{Al}_{2} \mathrm{O}_{3}$ exposed to $420 \mathrm{ppb} \mathrm{O}_{3}$ at $t=0 \mathrm{~min}$ (black) and 500 min (red).

\subsection{Ozonolysis of 4-propylguaiacol}

We studied the heterogeneous ozonolysis of NaCl- and $\alpha$ $\mathrm{Al}_{2} \mathrm{O}_{3}$-adsorbed 4-propylguaiacol at $0 \% \mathrm{RH}$ with $\mathrm{O}_{3}$ concentrations ranging from 150 to $990 \mathrm{ppb}$. Figure 3 shows $t=0$ (black) and $t=500$ (color) minute reaction spectra on (a) $\mathrm{NaCl}$ at $551 \mathrm{ppb} \mathrm{O}_{3}$ and on (b) $\alpha-\mathrm{Al}_{2} \mathrm{O}_{3}$ at $420 \mathrm{ppb} \mathrm{O}_{3}$. Dominant spectral features associated with condensed-phase products include peaks at 1745 and $1722 \mathrm{~cm}^{-1}$ assigned to carboxylic acid or aldehyde carbonyl vibrations (Socrates, 2001). Loss of aromatic $\mathrm{CH}$ and ring stretching vibrations at 3056 and $1518 \mathrm{~cm}^{-1}$, respectively, imply that ozonolysis cleaved the aromatic ring. $\alpha-\mathrm{Al}_{2} \mathrm{O}_{3}$-adsorbed products also exhibited a strong peak at $1610 \mathrm{~cm}^{-1}$, which was not as significant for $\mathrm{NaCl}$-adsorbed products, consistent with carboxylate vibrations (Socrates, 2001). Similar substrate differences were seen for muconic acid formed from the heterogeneous ozonolysis of surface-adsorbed catechol (Woodill et al., 2013).

To identify reaction products, we extracted the products from reacted $\mathrm{NaCl}$-adsorbed 4-propylguaiacol samples in acetonitrile for analysis using GC-MS. After derivatization with BSTFA, the total ion current chromatogram displayed two main peaks corresponding to unreacted 4propylguaiacol and a single product at 12.7 and $13.7 \mathrm{~min}$, respectively (Fig. 4a). Figure 4b displays the mass spectrum of the 13.7 min product peak. Although not prominent in the mass spectrum, we identify the parent ion for this product as $m / z=270$ (see extracted ion chromatogram in Fig. 4a). Without BSTFA derivatization, the parent ion $\mathrm{m} / z$ was 198 , indicating the presence of a single alcohol or acid group. Major fragmentation peaks in the mass spectrum of Fig. $4 \mathrm{~b}$ include $255\left(\mathrm{M}-\mathrm{CH}_{3}\right), 211\left(\mathrm{M}-\mathrm{CO}_{2} \mathrm{CH}_{3}\right), 153(\mathrm{M}-$ $\left.\mathrm{CO}_{2} \mathrm{SiMe}_{3}\right)$, and $73\left(\mathrm{SiMe}_{3}\right)$, which are consistent with the ring-cleaved product included in Reaction (R2).

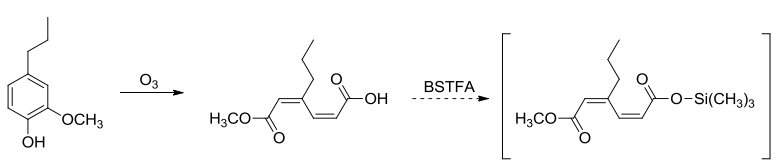

${ }^{1} \mathrm{H}-\mathrm{NMR}$ analysis of $\mathrm{NaCl}$-adsorbed 4-propylguaiacol $+\mathrm{O}_{3}$ reaction samples extracted in $d_{6}$-acetone confirmed this primary product structure (Supplement, Fig. S2; $\delta_{\mathrm{H}}(200 \mathrm{MHz}$, $d_{6}$-acetone, $\left.\mathrm{Me}_{4} \mathrm{Si}\right) 0.9\left(3 \mathrm{H}, t, \mathrm{CH}_{3}\right), 1.5\left(2 \mathrm{H}, m, \mathrm{CH}_{2} \mathrm{CH}_{3}\right)$, $2.4\left(2 \mathrm{H}, t, \mathrm{CH}_{2}\right), 3.6\left(3 \mathrm{H}, s, \mathrm{OCH}_{3}\right), 5.7(1 \mathrm{H}, s$, gem$\left.\mathrm{CO}_{2} \mathrm{CH}_{3}\right), 5.9\left(1 \mathrm{H}, d\right.$, gem- $\left.-\mathrm{CO}_{2} \mathrm{H}\right), 7.1(1 \mathrm{H}, d$, gem-C=C) $)$. In total, both the GC-MS and NMR data indicate that the 

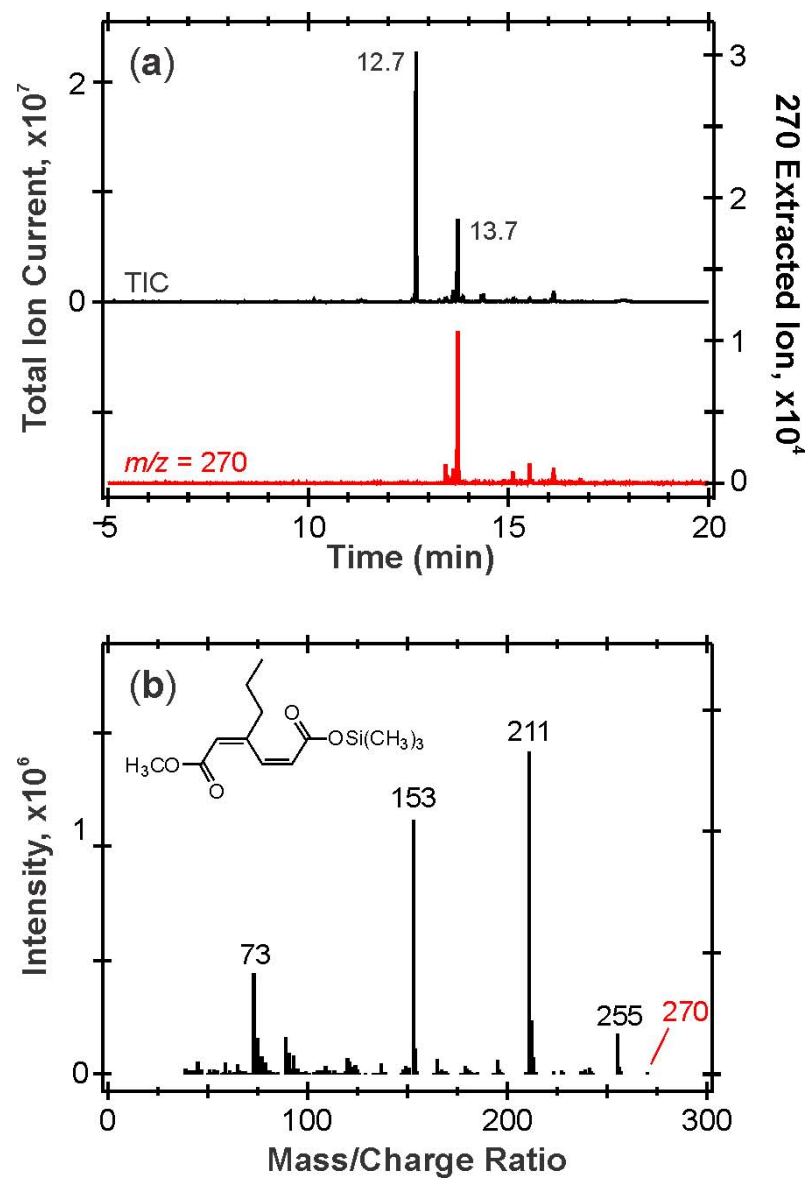

Fig. 4. (a) Total ion current gas chromatogram (black) and $m / z=$ 270 extracted ion chromatogram (red) of products extracted from 4propylguaiacol ozonolysis sample. (b) Mass spectrum of $13.7 \mathrm{~min}$ peak assigned as ring-cleaved product.

DRIFTS reaction spectra discussed above correlate with the ozonolysis ring cleavage depicted in Reaction (R2).

In contrast to our results, cleavage of the aromatic ring was not observed in previous investigations of the heterogeneous ozonolysis of surface-adsorbed methoxyphenols (e.g., Net et al., 2011). Substrate effects and sample preparation might explain this discrepancy. These prior studies coated silica particles using a liquid-solid adsorption method where the organic and substrate were mixed in a solvent, which was then evaporated off. Here, we used semivolatile methoxyphenols that could be coated on $\mathrm{NaCl}$ and $\alpha-\mathrm{Al}_{2} \mathrm{O}_{3}$ substrates via gas-solid adsorption. We previously noted that under dry conditions, thin film catechol did not react with ozone (Barnum et al., 2011), while $\mathrm{NaCl}$ - and $\alpha-\mathrm{Al}_{2} \mathrm{O}_{3}$-adsorbed catechol readily reacted with ozone (Woodill et al., 2012), indicating that these substrates can greatly enhance this ozonolysis chemistry. Attempts to coat silica with catechol and various methoxyphenols via our DRIFTS technique resulted in reversible adsorption, where purging with dry air dramatically decreased the organic surface concentration. This sug- gests that substrate-methoxyphenol interactions are considerably weaker for silica compared to $\mathrm{NaCl}$ and $\alpha-\mathrm{Al}_{2} \mathrm{O}_{3}$, which in turn may impact the 1,3-cycloaddition of ozone to these adsorbed aromatic rings.

To evaluate the reaction kinetics for the ozonolysis of surface-adsorbed 4-propylguaiacol, DRIFTS reaction spectra were recorded continuously with averaging times of approximately $3 \mathrm{~min}$. Integration of the key infrared spectral features described above as a function of time facilitated the kinetic analysis of 4-propylguaiacol consumption and product formation. Figure 5a reports one such analysis for $\mathrm{NaCl}-$ adsorbed 4-propylguaiacol exposed to $665 \mathrm{ppb} \mathrm{O}_{3}$, showing the normalized integrated area of the $3058 \mathrm{~cm}^{-1}$ peak (i.e., 4-propylguaiacol) decaying concurrently with the growth of the $1745 \mathrm{~cm}^{-1}$ product peak. A general rate equation for this reaction can be written as

Rate $=k\left[\mathrm{O}_{3}\right]^{x}[4 \mathrm{PG}]^{y}$.

Due to the continuous flow of carrier gas through the DRIFTS reaction chamber, the ozone concentration is assumed to be constant during the course of an experiment. Therefore, the experimental rate can be approximated as

Rate $=k_{\exp }[4 \mathrm{PG}]^{y}$.

An exponential decay function fit the loss of aromatic $\mathrm{CH}$ stretching vibrations, indicating the reaction was first order with respect to 4-propylguaiacol with a pseudo-first-order rate constant of $k_{\exp }=1.95 \times 10^{-4} \mathrm{~s}^{-1}$. A first-order productintegrated rate expression fit the carbonyl formation kinetics with a rate constant $k_{\exp }=1.50 \times 10^{-4} \mathrm{~s}^{-1}$. The similarity of these rate constants supports a direct correspondence between 4-propylguaiacol consumption and carbonyl product formation. Figure $5 \mathrm{~b}$ collates the experimental rate constants for all experiments plotted against ozone concentration. Linear fits to this data are included as solid lines and correspond to an Eley-Rideal-type mechanism, where gaseous ozone would react directly with adsorbed 4-propylguaiacol,

$\mathrm{O}_{3}(\mathrm{~g})+4-\mathrm{PG}(\mathrm{ads}) \rightarrow$ products

$k_{\exp }=k_{\mathrm{O}_{3}} \cdot\left[\mathrm{O}_{3}\right]$.

Linear best-fit parameters find $k_{\mathrm{O}_{3}}=1.0 \times 10^{-17} \mathrm{~cm}^{3} \mathrm{~mol}-$ ecules $^{-1} \mathrm{~s}^{-1}$ and $7.0 \times 10^{-19} \mathrm{~cm}^{3}$ molecules ${ }^{-1} \mathrm{~s}^{-1}$ for 4propylguaiacol adsorbed on $\mathrm{NaCl}$ and $\alpha-\mathrm{Al}_{2} \mathrm{O}_{3}$, respectively.

The heterogeneous ozonolysis of many similar surfaceadsorbed organics follow a Langmuir-Hinshelwood mechanism (Dubowski et al., 2004; Lu et al., 2011; Kwamena et al., 2004, 2007; Zhou et al., 2012; Rosen et al., 2008) in which gaseous ozone first adsorbs to the surface before reacting with adsorbed 4-propylguaiacol:

$\mathrm{O}_{3}(\mathrm{~g}) \leftrightarrow \mathrm{O}_{3}$ (ads), 

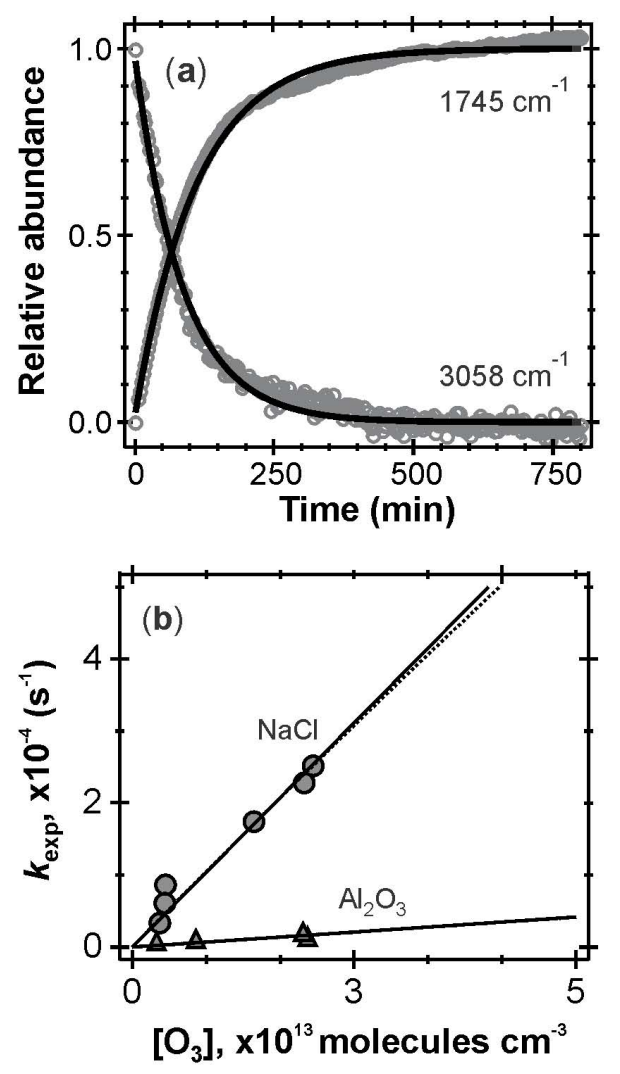

Fig. 5. (a) Kinetics integration of $3058 \mathrm{~cm}^{-1}$ peak (4propylguaiacol aromatic $\mathrm{CH}$ stretch) and $1745 \mathrm{~cm}^{-1}$ peak (product carbonyl vibration). Exponential fits find $k_{\exp }=1.95 \times 10^{-4} \mathrm{~s}^{-1}$ and $1.50 \times 10^{-4} \mathrm{~s}^{-1}$ for 3058 and $1745 \mathrm{~cm}^{-1}$ peaks, respectively.

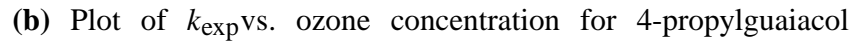
adsorbed on $\mathrm{NaCl}$ (circles) and $\alpha-\mathrm{Al}_{2} \mathrm{O}_{3}$ (triangles). Solid line fits correspond to Eley-Rideal-type mechanism; dashed line fits correspond to Langmuir-Hinshelwood mechanism.

$\mathrm{O}_{3}(\mathrm{ads})+4-\mathrm{PG}(\mathrm{ads}) \rightarrow$ products.

For the Langmuir-Hinshelwood mechanism, the experimental rate constant would be

$k_{\exp }=\frac{k_{\max } \cdot K_{\mathrm{O}_{3}} \cdot\left[\mathrm{O}_{3}\right]}{1+K_{\mathrm{O}_{3}} \cdot\left[\mathrm{O}_{3}\right]}$,

where $K_{\mathrm{O}_{3}}$ is the ozone adsorption equilibrium constant for Reaction (R4) and $k_{\max }$ is the maximum rate constant for Reaction (R5). Langmuir-Hinshelwood fits, which are included as dashed lines in Fig. 5b, are indistinguishable from the linear fits at the relatively low ozone concentrations used in this study, preventing us from conclusively identifying the reaction mechanism. (Langmuir-Hinshelwood bestfit parameters in Fig. $5 \mathrm{~b}$ are $k_{\max }=0.0102 \mathrm{~s}^{-1}$ and $K_{\mathrm{O}_{3}}=$ $1.0 \times 10^{-15} \mathrm{~cm}^{3}$ for $\mathrm{NaCl}$ and $k_{\max }=0.0083 \mathrm{~s}^{-1}$ and $K_{\mathrm{O}_{3}}=$ $8.4 \times 10^{-17} \mathrm{~cm}^{3}$ for $\alpha-\mathrm{Al}_{2} \mathrm{O}_{3}$. Since our data do not show signs of approaching saturation, these parameters are poorly constrained, and only the values of $k_{\max }$ times $K_{\mathrm{O}_{3}}$ are known with certainty.) Higher ozone concentrations, which would be required to distinguish between these two mechanisms, are unfortunately not feasible with our current experimental setup.

Although future work would be required to conclusively determine which heterogeneous mechanism is operative for the ozonolysis of adsorbed 4-propylguaiacol, this kinetic analysis allows us to estimate the atmospheric lifetime of these systems. Equations (5) and (6) calculate atmospheric lifetimes assuming the Eley-Rideal and LangmuirHinshelwood mechanisms, respectively.

$$
\begin{array}{r}
\tau=\frac{1}{k_{\mathrm{O}_{3}}\left[\mathrm{O}_{3}\right]} \\
\tau=\frac{1+K_{\mathrm{O}_{3}}\left[\mathrm{O}_{3}\right]}{k_{\max } K_{\mathrm{O}_{3}}\left[\mathrm{O}_{3}\right]}
\end{array}
$$

Assuming a tropospheric ozone concentration of $40 \mathrm{ppb}$ (Vingarzan, 2004), the atmospheric lifetime for 4propylguaiacol adsorbed on $\mathrm{NaCl}$ is estimated to be 27.7 to $28.2 \mathrm{~h}$, depending on the mechanism, vs. 17 days when adsorbed on $\alpha-\mathrm{Al}_{2} \mathrm{O}_{3}$.

\subsection{Eugenol and isoeugenol $+\mathrm{O}_{3}$}

After conclusively identifying ozone-induced ring cleavage for 4-propylguaiacol, we used identical methods and conditions to investigate the heterogeneous ozonolysis of surface-adsorbed eugenol and isoeugenol. Figure 6 shows initial (black) and final (red) DRIFTS reaction spectra for (a) $\mathrm{NaCl}$-eugenol exposed to $424 \mathrm{ppb} \mathrm{O}_{3}$ and (b) $\mathrm{NaCl}-$ isoeugenol $+180 \mathrm{ppb} \mathrm{O}_{3}$. Both systems exhibit the loss of alkene side-chain spectral features and the formation of a dominant product carbonyl vibration near $1730 \mathrm{~cm}^{-1}$. Also evident in these product spectra is the diminishing intensity of the aromatic ring vibration at $1518 \mathrm{~cm}^{-1}$, indicating the loss of some aromatic ring structures.

To monitor the ozonolysis kinetics of the alkene side chain vs. across the methoxyphenol, we integrated vibrational features unique to these two sites of attack. Figure 7 shows one set of integrations for the reaction of $\mathrm{NaCl}$-adsorbed isoeugenol exposed to $180 \mathrm{ppb} \mathrm{O}_{3}$. The alkene side-chain spectral feature at $3064 \mathrm{~cm}^{-1}$ decayed rapidly with a rate constant of $k_{1}=7.50 \times 10^{-4} \mathrm{~s}^{-1}$. Features associated with the methoxyphenol aromatic structure, including vibrations at 1518 and $1380 \mathrm{~cm}^{-1}$, decayed much more slowly with $k_{2}=0.40 \times 10^{-4} \mathrm{~s}^{-1}$. Growth of the product carbonyl feature at $1726 \mathrm{~cm}^{-1}$ could not be successfully fit with a single exponential function; a double-exponential product growth function did fit these data with $k_{1}=4.4 \times 10^{-4} \mathrm{~min}^{-1}$ and $k_{2}=0.30 \times 10^{-4} \mathrm{~s}^{-1}$, in good agreement with the loss of the alkene side-chain and methoxyphenol spectral features, respectively. The amplitude of the second, slower exponential function was twice that of the first, more rapid function. These amplitudes are consistent with the fact that ozonolysis 


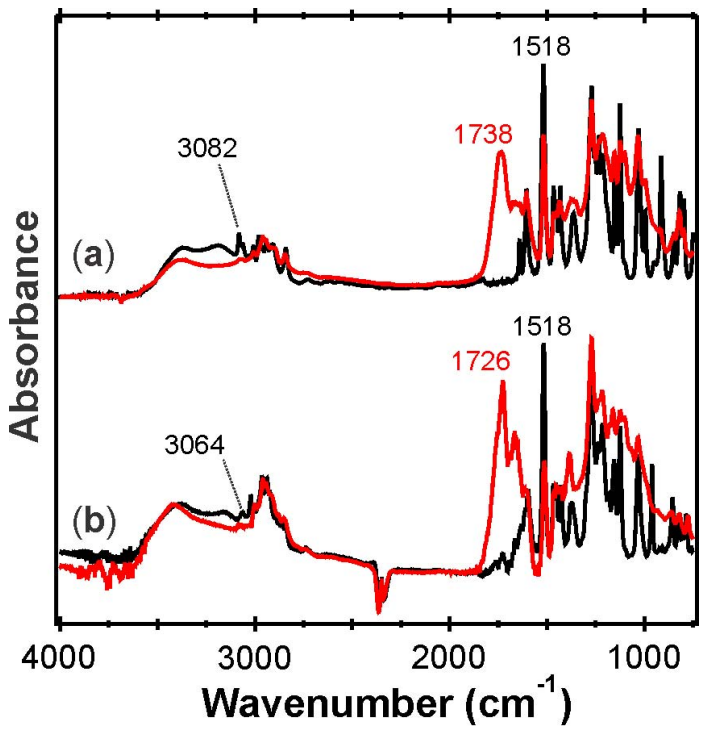

Fig. 6. DRIFTS spectra of (a) eugenol adsorbed on $\mathrm{NaCl}$ exposed to $424 \mathrm{ppb} \mathrm{O}_{3}$ at $t=0 \mathrm{~min}$ (black) and $340 \mathrm{~min}$ (red), and (b) isoeugenol adsorbed on $\mathrm{NaCl}$ exposed to $180 \mathrm{ppb} \mathrm{O}_{3}$ at $t=$ 0 min (black) and $800 \mathrm{~min}$ (red).

of the alkene side chain is expected to form one condensedphase aldehyde or carboxylic acid functional group, while slower ring cleavage should form two condensed-phase carbonyl functional groups. Reaction Scheme (R6) depicts the condensed-phase products consistent with this kinetic analysis, and an analogous mechanism could be constructed for the ozonolysis of eugenol. It should be noted that the rate constant for cleavage of the aromatic ring, $k_{2}$, actually corresponds to ozonolysis of vanillic acid and vanillin and not isoeugenol since the data were fit after $t=100 \mathrm{~min}$, by which time essentially all the alkene side chains were oxidized.

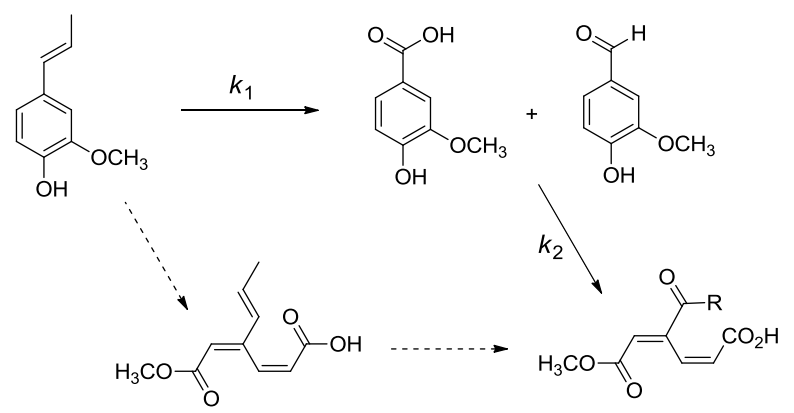

GC-MS analysis of $\mathrm{NaCl}$-adsorbed isoeugenol exposed to ozone revealed unreacted isoeugenol and three major product peaks (see Supplement, Fig. S3). The largest product peak, which accounted for $54 \%$ of the total product peak areas, was identified with confidence by comparison to the NIST library as vanillic acid (BSFTA derivatized $\mathrm{m} / \mathrm{z}: 312$ $\left.\left(\mathrm{M}^{+}\right), 297\left(\mathrm{M}-\mathrm{CH}_{3}\right), 267\left(\mathrm{M}-3 \times \mathrm{CH}_{3}\right)\right)$. Vanillin accounted for $29 \%$ of the integrated product peak areas (BSFTA derivatized $\left.m / z: 224\left(\mathrm{M}^{+}\right), 209\left(\mathrm{M}-\mathrm{CH}_{3}\right), 194\left(\mathrm{M}-2 \times \mathrm{CH}_{3}\right)\right)$, while the third peak, which accounted for $17 \%$, could not be conclusively identified but shows fragmentation patterns consistent with a silated methoxyphenol species. Although several minor peaks appeared in the total ion chromatogram, no peak could be conclusively identified as ring-cleaved products. The total ion current chromatogram for extracted eugenol ozonolysis samples showed unreacted eugenol and five significant product peaks (Supplement, Fig. S4). Only two product peaks were conclusively identified by comparison to the NIST library: homovanillic acid (BSFTA derivatized $m / z: 326\left(\mathrm{M}^{+}\right), 209\left(\mathrm{M}-\mathrm{CO}_{2} \mathrm{SiMe}_{3}\right), 179(\mathrm{M}-$ $\left.\mathrm{CO}_{2} \mathrm{SiMe}_{3}-2 \times \mathrm{CH}_{3}\right)$ ) and homovanillin (BSFTA derivatized $\left.m / z: 238\left(\mathrm{M}^{+}\right), 209\left(\mathrm{M}-\mathrm{COH}-2 \times \mathrm{CH}_{3}\right), 179\right)$. Two of the remaining peaks are tentatively assigned to artifacts resulting from the BSTFA derivatization of homovanillin (see Supplement), while the remaining peak could not be conclusively identified but is consistent with a methoxyphenol species. ${ }^{1} \mathrm{H}$-NMR spectra of $d_{6}$-acetone-extracted eugenol reaction mixtures were difficult to interpret since most of the product peaks overlapped with unreacted eugenol features. Two discernible product features are noteworthy: aromatic peaks between $\delta_{\mathrm{H}}=6.5$ and $7.0 \mathrm{ppm}$ and an aldehyde peak at $\delta=9.7 \mathrm{ppm}$, consistent with the formation of homovanillin and homovanillic acid. No evidence of higher molecular weight products was detected, although admittedly our GCMS analysis is not ideally suited to their detection due to reversible dissociation during extraction (Jang et al., 2002). Prior investigations have identified gaseous formaldehyde for the ozonolysis of liquid eugenol (Sachdev et al., 1972), which is likely also produced in these systems.

Although GC-MS and NMR analysis did not conclusively identify ring-cleaved products for the ozonolysis of eugenol and isoeugenol, we believe the similarities with 4-propylguaiacol combined with the kinetic analysis discussed above provide strong evidence that ozone does attack the methoxyphenol of eugenol and isoeugenol, resulting in cleavage of the aromatic ring, albeit at rates an order of magnitude slower than ozonolysis of the alkene side chains. Ozonolysis of both the alkene side-chain and methoxyphenol features appeared to be first order with respect to ozone concentration. Estimates of the relative reaction rates and atmospheric lifetimes, assuming an Eley-Rideal mechanism, for all systems studied here are collated in Table 2. Two general trends emerge from the collective analysis of these results: (1) ozonolysis of surface-adsorbed methoxyphenols occurs at a rate approximately 10 times slower than ozonolysis of alkene side chains, and (2) substrate effects suggest these ozonolysis reactions are faster on $\mathrm{NaCl}$ vs. $\alpha-\mathrm{Al}_{2} \mathrm{O}_{3}$. A comparison to catechol ozonolysis data from Woodill et al. (2013) also suggests that ring cleavage of ortho-diols is 4-10 times faster than ortho-methoxyphenols.

We also conducted a complementary set of experiments using an ATR-FTIR reaction cell to investigate the 
Table 2. Relative ozonolysis kinetics.

\begin{tabular}{|c|c|c|c|c|c|}
\hline Substrate & Organic & $k_{\mathrm{O}_{3}}^{\mathrm{a}}$ & $\begin{array}{c}\text { Relative } \\
\text { Rate }^{b}\end{array}$ & $\begin{array}{c}\text { Atmospheric } \\
\text { Lifetime }^{\mathrm{c}}\end{array}$ & $\gamma$ \\
\hline $\mathrm{NaCl}$ & catechol $^{\mathrm{d}}$ & $6.3 \times 10^{-17}$ & 91 & $4.5 \mathrm{~h}$ & $1.5 \times 10^{-6}$ \\
\hline$\alpha-\mathrm{Al}_{2} \mathrm{O}_{3}$ & catechol $^{\mathrm{d}}$ & $1.5 \times 10^{-17}$ & 22 & $18 \mathrm{~h}$ & $3.5 \times 10^{-7}$ \\
\hline $\mathrm{NaCl}$ & 4-propylguaiacol & $1.0 \times 10^{-17}$ & 14 & $28 \mathrm{~h}$ & $2.3 \times 10^{-7}$ \\
\hline$\alpha-\mathrm{Al}_{2} \mathrm{O}_{3}$ & 4-propylguaiacol & $7.0 \times 10^{-19}$ & 1 & 17 days & $1.6 \times 10^{-8}$ \\
\hline $\mathrm{NaCl}$ & eugenol, alkene & $3.6 \times 10^{-17}$ & 51 & $7.9 \mathrm{~h}$ & $8.3 \times 10^{-7}$ \\
\hline $\mathrm{NaCl}$ & eugenol, ring & $7.9 \times 10^{-18}$ & 11 & 1.5 days & $1.8 \times 10^{-7}$ \\
\hline$\alpha-\mathrm{Al}_{2} \mathrm{O}_{3}$ & eugenol, alkene & $5.2 \times 10^{-17}$ & 74 & $5.5 \mathrm{~h}$ & $1.2 \times 10^{-6}$ \\
\hline$\alpha-\mathrm{Al}_{2} \mathrm{O}_{3}$ & eugenol, ring & $5.1 \times 10^{-18}$ & 7 & 2.3 days & $1.2 \times 10^{-7}$ \\
\hline $\mathrm{NaCl}$ & isoeugenol, alkene & $1.3 \times 10^{-16}$ & 193 & $2.1 \mathrm{~h}$ & $3.1 \times 10^{-6}$ \\
\hline $\mathrm{NaCl}$ & isoeugenol, ring & $7.9 \times 10^{-18}$ & 11 & 1.5 days & $1.8 \times 10^{-7}$ \\
\hline$\alpha-\mathrm{Al}_{2} \mathrm{O}_{3}$ & isoeugenol, alkene & $2.7 \times 10^{-17}$ & 38 & $11 \mathrm{~h}$ & $6.2 \times 10^{-7}$ \\
\hline$\alpha-\mathrm{Al}_{2} \mathrm{O}_{3}$ & isoeugenol, ring & $6.7 \times 10^{-18}$ & 10 & 1.7 days & $1.6 \times 10^{-7}$ \\
\hline
\end{tabular}

a Assumes Eley-Rideal mechanism; $\mathrm{cm}^{3}$ molecules ${ }^{-1} \mathrm{~s}^{-1}$.

${ }^{\mathrm{b}}$ Estimated using $k_{\mathrm{O}_{3}}$.

${ }^{c}$ Atmospheric lifetimes calculated assuming $40 \mathrm{ppb}$ tropospheric ozone concentration.

${ }^{\mathrm{d}}$ Catechol rates from data included in Woodill et al. (2013).

heterogeneous ozonolysis of $\alpha-\mathrm{Al}_{2} \mathrm{O}_{3}$-adsorbed eugenol. A thin film of $\alpha-\mathrm{Al}_{2} \mathrm{O}_{3}$ was first coated on a ZnSe ATR crystal, then exposed to gaseous eugenol, and finally exposed to $209 \mathrm{ppb} \mathrm{O}_{3}$ at $0 \%$ relative humidity. Control experiments exposing a clean $\mathrm{ZnSe}$ crystal to gaseous eugenol showed no significant condensed-phase organic features, indicating that $\mathrm{ZnSe}$ did not act as a reactive substrate in these experiments. Ozonolysis reaction spectra are included in the Supplement, Fig. S5. Inspection of the $t=0 \mathrm{~min}$ ATR spectrum reveals notable differences compared to DRIFTS spectra, with no negative $\alpha-\mathrm{Al}_{2} \mathrm{O}_{3}$ surface hydroxyl peak at $3734 \mathrm{~cm}^{-1}$, and the presence of $\mathrm{OH}$ stretching and bending vibrations at 3420 and $1373 \mathrm{~cm}^{-1}$, respectively. These features suggest physisorption of eugenol rather than monodentate binding, which is likely due to differences in sample preparation. Subsequent ozonolysis produced spectral features consistent with DRIFTS reaction spectra, including the rapid loss of alkene side-chain peaks at 1639 and $3082 \mathrm{~cm}^{-1}$, slower loss of aromatic features at 1518 and $3015 \mathrm{~cm}^{-1}$, and the formation of carbonyl peak at $1734 \mathrm{~cm}^{-1}$. Reaction rate constants were consistent with DRIFTS experiments.

Reactive uptake coefficients quantify heterogeneous reaction kinetics as the fraction of $\mathrm{O}_{3}$-surface collisions that result in product formation relative to the total number of $\mathrm{O}_{3}$ surface collisions. Reactive uptake coefficients can be calculated from the ATR kinetic data by calibrating the FTIR spectral features assuming a eugenol surface concentration of $3 \times 10^{18}$ molecules $\mathrm{m}^{-2}$ at $t=0 \mathrm{~min}$. The initial loss rate was then determined by linear fits to the first $20 \mathrm{~min}$ for the key spectral features discussed above. These loss rates were then compared to the frequency of total $\mathrm{O}_{3}$-surface colli- sions, which was calculated using the kinetic theory of gases. Analyzing the rate of decay of the alkene side-chain spectral features yielded an initial reactive uptake coefficient of $\gamma=1.2 \times 10^{-6}$. The heterogeneous ozonolysis of long-chain aliphatic alkenes, such as oleic acid, has been extensively studied. Uptake coefficients from these studies span a vast range, from $1.6 \times 10^{-3}$ for oleic acid-generated particles (Morris et al., 2002; Hearn et al., 2005) to $8 \times 10^{-4}$ for liquid oleic acid coatings (Moise and Rudich, 2002; Thornberry and Abbatt, 2004) down to $2.6 \times 10^{-6}$ for oleic acid monolayers spread on aqueous droplets (Gonzalez-Labrada et al., 2007). Dubowski et al. (2004) studied the ozonolysis of C3 and C8 vinyl terminated self-assembled monolayers (SAMs) and measured initial reaction probabilities around $\gamma \sim 10^{-5}$ for ozone concentrations below $10^{13}$ molecules $\mathrm{cm}^{-3}$; uptake coefficients decreased with increasing ozone concentrations, consistent with a Langmuir-Hinshelwood mechanism. This wide range of uptake coefficients is likely the result of ozone diffusion into and reaction with the bulk of liquid coatings and particles. SAMs, on the other hand, necessarily only involve surface reactions, although experimental evidence suggests that ozone still has residence times on the order of $7 \mathrm{~s}$ (Dubowski et al., 2004). The surface-adsorbed organics employed in the present study, with near-monolayer surface concentrations, have uptake coefficients at the lower end of this range consistent with SAMs and oleic acid monolayers.

Combining the alkene side-chain uptake coefficient $(\gamma=$ $1.2 \times 10^{-6}$ ) with the relative rates implies that ozonolysis across the methoxyphenol has a reactive uptake coefficient of approximately $1 \times 10^{-7}$, while the ozonolysis of $\mathrm{NaCl}-$ adsorbed catechol is predicted to be an order of magnitude 


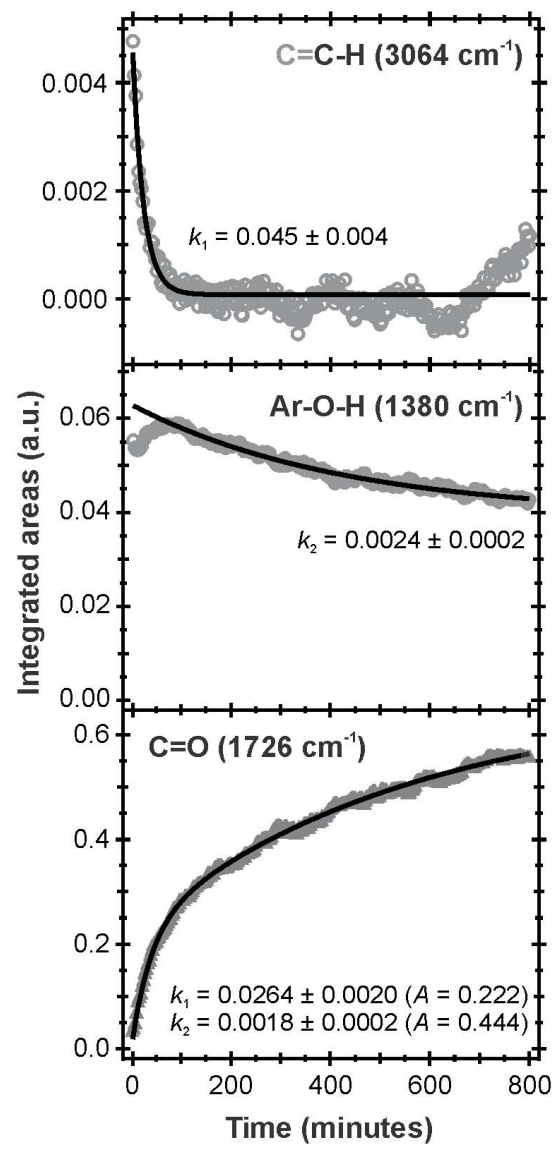

Fig. 7. Reaction kinetics for the ozonolysis of $\mathrm{NaCl}$-adsorbed isoeugenol at $180 \mathrm{ppb} \mathrm{O}_{3}$ depicting (top) rapid consumption of the alkene side chain, (middle) slower decay of the aromatic ring, and (bottom) product carbonyl formation, which required a doubleexponential function with rate constants consistent with competitive alkene side-chain vs. methoxyphenol ozonolysis.

faster with $\gamma=1.6 \times 10^{-6}$ (Table 2). Knopf et al. (2011) measured $\gamma=8.3 \times 10^{-5}$ for $\mathrm{O}_{3}$ on thin film nitroguaiacol, almost three orders of magnitude faster than the current estimate. Barnum et al. (2012) found thin film crystalline catechol to have $\gamma=5.6 \times 10^{-5}$ at $81 \%$ relative humidity. These differences may be due in part to the diffusion of ozone several layers into the solid thin films allowing for reaction with subsurface compounds. For instance, frozen oleic acid films have uptake coefficients of $\gamma=5.2 \times 10^{-5}$ to $7.1 \times 10^{-4}$, which are less than those of liquid oleic acid films due to limited reaction with the bulk (Moise and Rudich, 2002; Thornberry and Abbatt, 2004), but still more than an order of magnitude greater than for SAMs and monolayers. For the reaction of 4-nitroguaiacol, it is also possible that product channels other than ring cleavage are involved, and additional experiments identifying reaction products are required to evaluate this potential.

\subsection{Impact of relative humidity}

Given the importance of co-adsorbed water in atmospheric heterogeneous chemistry, we investigated the heterogeneous ozonolysis of eugenol as a function of relative humidity. DRIFTS samples were baked and then equilibrated at the selected relative humidity by adjusting the flow rates of dry and wet carrier gas. Once equilibrated, the dry flow was directed through the eugenol bubbler such that coating of the samples occurred at the selected relative humidity. Spectral features for both $\mathrm{NaCl}$ - and $\alpha-\mathrm{AL}_{2} \mathrm{O}_{3}$-adsorbed eugenol at higher $\mathrm{RH}$ were identical to those discussed above for dry conditions, although the overall intensity decreased with increasing RH. This indicated that co-adsorbed water competed with eugenol for surface binding sites, resulting in lower eugenol surface concentrations at higher humidity. This effect was more significant for $\mathrm{NaCl}$, where increasing the humidity to $21 \% \mathrm{RH}$ decreased the adsorbed eugenol surface concentration by one-half (i.e., half a monolayer coverage, $\theta=0.5$ ). In comparison, $\alpha-\mathrm{Al}_{2} \mathrm{O}_{3}$-adsorbed eugenol maintained $\theta=0.85$ surface coverage at $25 \%$ and did not decrease to half a monolayer $(\theta=0.54)$ until the humidity was increased to $75 \%$. Finally, for both $\mathrm{NaCl}$ and $\alpha-\mathrm{Al}_{2} \mathrm{O}_{3}$, increasing the relative humidity had no discernible effect on the pseudo-first-order rate constants, within the experimental uncertainty, determined for the heterogeneous ozonolysis of surface-adsorbed eugenol. Similar humidity-independent results were observed for the heterogeneous ozonolysis of liquid oleic acid, linoleic acid, and linolenic acid films (Thornberry and Abbatt, 2004). Barnum et al. (2012) found that higher humidities increased the reactive uptake coefficients for the heterogeneous ozonolysis of thin film solid crystalline catechol as a result of hydrogen bonding interactions between adsorbed water and the diol. A similar effect is probably not operative in the current systems since the methoxyphenol binding interactions with the substrates outweigh interactions with co-adsorbed water. These results suggest that the heterogeneous reaction rates listed in Table 2 apply to both dry and humid conditions.

\subsection{Impact of solar radiation}

Surface-adsorbed eugenol exhibits an absorption maximum in the range of tropospheric actinic radiation $(\lambda>300 \mathrm{~nm})$. Figure 8 shows the diffuse reflectance UV-visible spectrum of $\mathrm{NaCl}$-adsorbed eugenol (i.e., $t=0 \mathrm{~min}$; black spectrum) with an absorption band centered at $341 \mathrm{~nm}$. After $100 \mathrm{~min}$ of exposure to $240 \mathrm{ppb} \mathrm{O}_{3}$ under dark conditions, this maximum absorbance shifted to $318 \mathrm{~nm}$ (blue spectrum). Continued exposure to ozone under dark conditions resulted in dramatically stronger absorbance in the UV region, with approximately $35 \%$ of $314 \mathrm{~nm}$ radiation absorbed following $1000 \mathrm{~min}$ of ozone exposure, and an absorption profile that tails out beyond $400 \mathrm{~nm}$ (red spectrum). The strong UV-visible absorption profiles of eugenol and its dark 


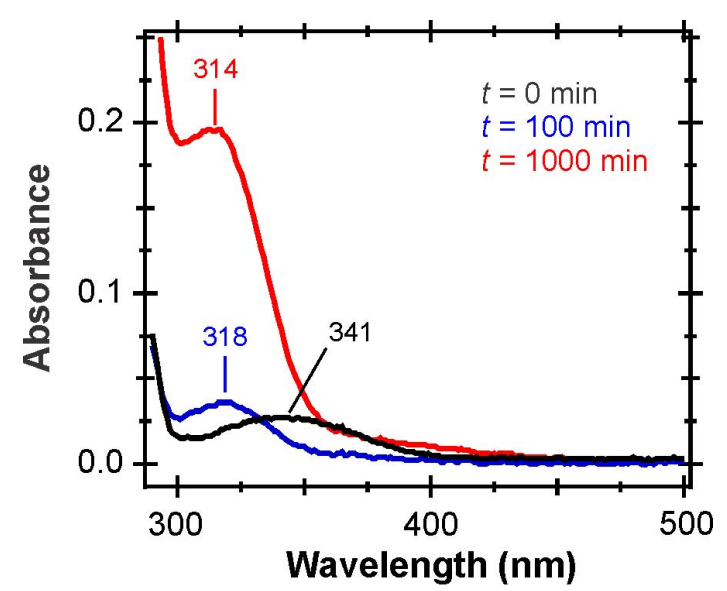

Fig. 8. Diffuse reflectance UV-visible absorbance spectra of $\mathrm{NaCl}-$ adsorbed eugenol exposed to $240 \mathrm{ppb} \mathrm{O}_{3}$ at $t=0,100$, and $1000 \mathrm{~min}$.

ozonolysis products raise the potential for photoenhanced ozonolysis chemistry under atmospheric conditions. Exposing surface-adsorbed eugenol to the solar simulator in the absence of ozone showed no discernible changes after several hours. We therefore investigated the heterogeneous ozonolysis of surface-adsorbed eugenol irradiated with the output of a xenon lamp solar simulator. Control experiments flowing $\mathrm{O}_{3}$ through an uncoated $\mathrm{NaCl}$ sample showed no changes in measured $\mathrm{O}_{3}$ concentration with the solar simulator on or off, indicating that photolysis of $\mathrm{O}_{3}$ at $\lambda>300 \mathrm{~nm}$ was negligible.

Figure 9 reports the reaction kinetics of key vibrational features during an experiment where $\mathrm{NaCl}$-adsorbed eugenol was exposed to $495 \mathrm{ppb} \mathrm{O}_{3}$ while the solar simulator was repeatedly turned on and off. The rate of decay of features associated with the alkene side chain (i.e., 3083 and $1638 \mathrm{~cm}^{-1}$ ) displayed no significant difference between light and dark conditions. Aromatic features, on the other hand, decayed at a faster rate when irradiated than under dark conditions. Experimental rate constants were determined for each segment of this plot by linear fits to a ln (integrated absorbance) vs. time plot, finding the photoenhanced rate to be $4( \pm 1)$ times faster than dark conditions. Growth of the product carbonyl $\left(1745 \mathrm{~cm}^{-1}\right)$, which contains contributions from both ozonolysis of the alkene side chain and the aromatic ring, also exhibited an increased rate when irradiated. Since neither $\mathrm{NaCl}$ nor $\alpha-\mathrm{Al}_{2} \mathrm{O}_{3}$ absorb radiation in the region of the solar simulator output, the observed photochemistry is likely the result of ozone reacting with photoexcited eugenol. Ozonolysis of coniferyl aldehyde adsorbed on silica particles was independent of irradiation conditions, although a slow aldehyde photolysis channel was also noted (Net et al., 2010a). The dominant ozonolysis reaction for coniferyl aldehyde involved attack of the alkene substituent, and is therefore consistent with our observa-

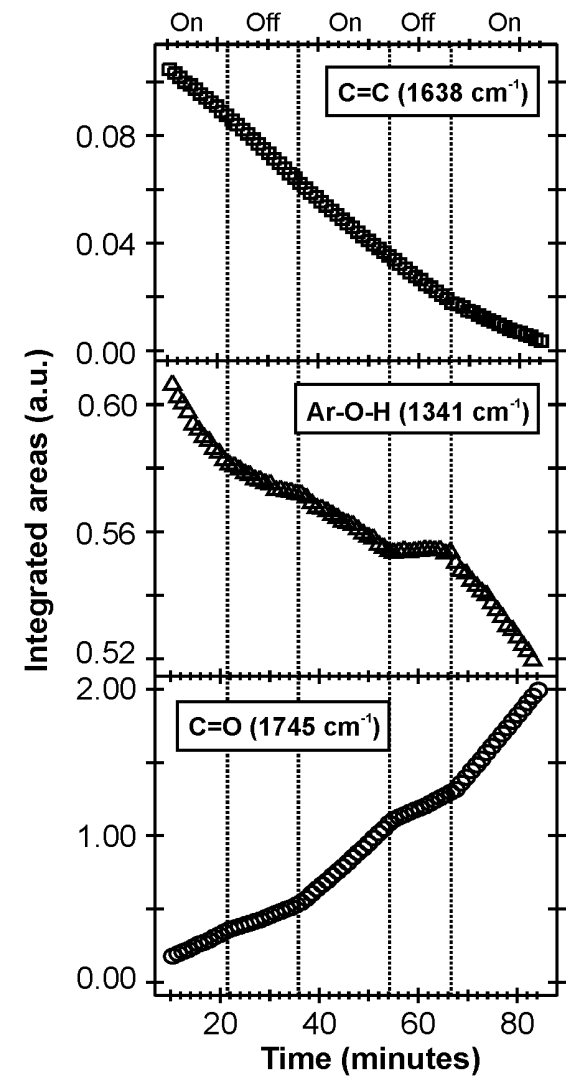

Fig. 9. Reaction kinetics for $\mathrm{NaCl}$-adsorbed eugenol exposed to $495 \mathrm{ppb} \mathrm{O}_{3}$ as a function of UV-visible radiation. Xenon lamp "on" and "off" labels indicate light and dark conditions, respectively. Phenol bend $\left(1341 \mathrm{~cm}^{-1}\right)$ and carbonyl $\left(1745 \mathrm{~cm}^{-1}\right)$ were photoenhanced, while the alkene side chain $\left(1638 \mathrm{~cm}^{-1}\right)$ was not.

tions for eugenol's side chain. In contrast, the ozonolysis of surface-adsorbed aromatic aldehydes (verataldehyde and 3,4,5-trimethoxybenzaldehyde) showed significant photoenhanced oxidation by an order of magnitude producing benzoic acid products (Net et al., 2010b, c). Our results demonstrate a similar, albeit smaller, photoenhancement for cleavage of the aromatic ring.

\section{Atmospheric implications and conclusions}

Biomass burning aerosol is a major source of atmospheric brown carbon, and laboratory studies have demonstrated that oxidation of select lignin pyrolysis products can generate UV-visible absorbing compounds. For instance, the $\mathrm{OH}$ oxidation of aqueous 3,5-dihydroxybenzoic acid produces oligomers that closely resemble HULIS and absorb strongly from the UV out to $500 \mathrm{~nm}$ (Hoffer et al., 2004). Secondary organic aerosol formed from the reaction of ozone with gaseous catechol and guaiacol also exhibit visible absorption profiles that stretch out beyond $500 \mathrm{~nm}$ (Ofner et al., 2011). Understanding the atmospheric fate of aerosol-bound 
lignin pyrolysis products is thus essential for understanding how oxidative processing affects aerosol chemical and physical properties, including UV-visible absorption. Heterogeneous ozonolysis represents one potential path for the oxidative processing of surface-adsorbed methoxyphenols (Net et al., 2010a, b, 2011; Knopf et al., 2011).

The present study quantifies the importance of aromatic ring cleavage as a result of ozone 1,3-cycloaddition across methoxyphenols adsorbed on $\mathrm{NaCl}$ and $\alpha-\mathrm{Al}_{2} \mathrm{O}_{3}$ substrates. Assuming that the kinetics of this process are similar for 4propylguaiacol, eugenol, and isoeugenol, the average uptake coefficient for ring cleavage of $\mathrm{NaCl}$-adsorbed methoxyphenols under dark conditions is $\gamma=2.3( \pm 0.8) \times 10^{-7}$, which corresponds to an atmospheric lifetime of 1.2 days assuming $40 \mathrm{ppb} \mathrm{O}_{3}$. The average uptake coefficient for $\alpha-\mathrm{Al}_{2} \mathrm{O}_{3}$ adsorbed methoxyphenols was $\gamma=9.7( \pm 7.3) \times 10^{-8}$, a factor of two slower, corresponding to an atmospheric lifetime of 2.8 days. UV-visible radiation $(\lambda>300 \mathrm{~nm})$ increased the rate of these reactions by a factor of $4( \pm 1)$, which will shorten these atmospheric lifetimes to under $24 \mathrm{~h}$. In comparison, ozonolysis of the alkene side chains for eugenol and isoeugenol, which was independent of UVvisible irradiation, reacted faster: $\mathrm{NaCl}$-adsorbed alkene attack, $\gamma=2( \pm 1) \times 10^{-6}$, lifetime $=3.3 \mathrm{~h}$; and $\alpha-\mathrm{Al}_{2} \mathrm{O}_{3}-$ adsorbed alkene attack, $\gamma=9( \pm 4) \times 10^{-7}$, lifetime $=7.2 \mathrm{~h}$. Although the ring cleavage reactions are slower, their estimated atmospheric lifetimes are shorter than the average lifetime of fine-mode particulates suspended in the troposphere. Thus, with aging of biomass burning aerosol, especially when transported through polluted urban environments, this heterogeneous ozonolysis chemistry will alter the chemical nature of adsorbed methoxyphenols.

Diffuse reflectance UV-visible spectroscopy demonstrates that these surface-adsorbed methoxyphenols absorb in the UV-A region (e.g., $\lambda_{\max }=341 \mathrm{~nm}$ for eugenol); however, their subsequent ozonolysis did not generate products that absorb strongly in the visible region. While these reactions will not directly produce brown carbon, they may indirectly impact this process. For instance, vanillic acid might react in a manner similar to 3,5-dihydroxybenzoic acid, which generates strong visible absorbers upon aqueous oxidation. The ozonolysis of surface-adsorbed vanillic acid might cleave the aromatic ring, thereby competing with this potential brown carbon formation process. The rate of this ozonolysis is dependent on several factors, including aerosol substrate and the nature of the substrate-organic interaction, as highlighted by the fact that previous laboratory studies did not observe aromatic ring cleavage for silica-adsorbed methoxyphenols, likely due to the different substrate and sample preparation. Thus, the importance of this chemistry in the atmosphere will depend on exact structure of the tropospheric aerosol under consideration, especially the nature of the the nature of the substrate-organic interaction.

\section{Supplementary material related to this article is available online at http://www.atmos-chem-phys.net/14/ 47/2014/acp-14-47-2014-supplement.pdf.}

Acknowledgements. This material is based upon work supported by the National Science Foundation under award no. AGS-0936920.

Edited by: M. Ammann

\section{References}

Bari, M. A., Baumbach, G., Kuch, B., and Scheffknecht, G.: Wood smoke as a source of particle-phase organic compounds in residential areas, Atmos. Environ., 43, 4722-4732, doi:10.1016/j.atmosenv.2008.09.006, 2009.

Barnum, T., Medeiros, N., and Hinrichs, R. Z.: Condensed-phase versus gas-phase ozonolysis of catechol: a combined experimental and theoretical study, Atmos. Environ., 55, 98-106, doi:10.1016/j.atmosenv.2012.02.019, 2012.

Coeur-Tourneur, C., Tomas, A., Guilloteau, A., Henry, F., Ledoux, F., Visez, N., Riffault, V., Wenger, J. C., and Bedjanian, Y.: Aerosol formation yields from the reaction of catechol with ozone, Atmos. Environ., 43, 2360-2365, doi:10.1016/j.atmosenv.2008.12.054, 2009.

Coeur-Tourneur, C., Foulon, V., and Lareal, M.: Determination of aerosol yields from 3-methylcatechol and 4-methylcatechol ozonolysis in a simulation chamber, Atmos. Environ., 44, 852857, doi:10.1016/j.atmosenv.2009.11.027, 2010.

Crutzen, P. J. and Andreae, M. O.: Biomass burning in the tropics - impact on atmospheric chemistry and biogeochemical cycles, Science, 250, 1669-1678, doi:10.1126/science.250.4988.1669, 1990.

Dubowski, Y., Vieceli, J., Tobias, D. J., Gomez, A., Lin, A., Nizkorodov, S. A., McIntire, T. M., and Finlayson-Pitts, B. J.: Interaction of gas-phase ozone at $296 \mathrm{~K}$ with unsaturated self-assembled monolayers: a new look at an old system, J. Phys. Chem. A, 108, 10473-10485, doi:10.1021/Jp046604x, 2004.

Falkovich, A. H. and Rudich, Y.: Analysis of semivolatile organic compounds in atmospheric aerosols by direct sample introduction thermal desorption GC/MS, Environ. Sci. Technol., 35, 2326-2333, 2001.

Frisch, M. J., Trucks, G. W., Schlegel, H. B., Scuseria, G. E., Robb, M. A., Cheeseman, J. R., Scalmani, G., Barone, V., Mennucci, B., Petersson, G. A., Nakatsuji, H., Caricato, M., Li, X., Hratchian, H. P., Izmaylov, A. F., Bloino, J., Zheng, G., Sonnenberg, J. L., Hada, M., Ehara, M., Toyota, K., Fukuda, R., Hasegawa, J., Ishida, M., Nakajima, T., Honda, Y., Kitao, O., Nakai, H., Vreven, T., Montgomery Jr., J. A., Peralta, J. E., Ogliaro, F., Bearpark, M., Heyd, J. J., Brothers, E., Kudin, K. N., Staroverov, V. N., Kobayashi, R., Normand, J., Raghavachari, K., Rendell, A., Burant, J. C., Iyengar, S. S., Tomasi, J., Cossi, M., Rega, N., Millam, J. M., Klene, M., Knox, J. E., Cross, J. B., Bakken, V., Adamo, C., Jaramillo, J., Gomperts, R., Stratmann, R. E., Yazyev, O., Austin, A. J., Cammi, R., Pomelli, C., Ochterski, J. W., Martin, R. L., Morokuma, K., Zakrzewski, V. G., Voth, G. A., Salvador, P., Dannenberg, J. J., Dapprich, S., Daniels, A. D., Farkas, O., Fores- 
man, J. B., Ortiz, J. V., Cioslowski, J., and Fox, D. J.: Gaussian 09, Revision A.02., Gaussian, Inc., Wallingford, CT, 2009.

Gelencser, A., Hoffer, A., Kiss, G., Tombacz, E., Kurdi, R., and Bencze, L.: In-situ formation of light-absorbing organic matter in cloud water, J. Atmos. Chem., 45, 25-33, 2003.

Ghosal, S., and Hemminger, J. C.: Surface adsorbed water on $\mathrm{NaCl}$ and its effect on nitric acid reactivity with $\mathrm{NaCl}$ powders, J. Phys. Chem. B, 108, 14102-14108, doi:10.1021/Jp047774c, 2004.

Gonzalez-Labrada, E., Schmidt, R., and DeWolf, C. E.: Kinetic analysis of the ozone processing of an unsaturated organic monolayer as a model of an aerosol surface, Phys. Chem. Chem. Phys., 9, 5814-5821, doi:10.1039/B707890k, 2007.

Hawthorne, S. B., Krieger, M. S., Miller, D. J., and Mathiason, M. B.: Collection and quantitation of methoxylated phenol tracers for atmospheric pollution from residential wood stoves, Environ. Sci. Technol., 23, 470-475, 1989.

Hawthorne, S. B., Miller, D. J., Langenfeld, J. J., and Krieger, M. S.: $\mathrm{PM}_{10}$ high-volume collection and quantitation of semi- and nonvolatile phenols, methoxylated phenols, alkanes, and polycyclic aromatic hydrocarbons for winter urban air and their relationship to wood smoke emissions, Environ. Sci. Technol., 26, 22512262, 1992.

Hearn, J. D., Lovett, A. J., and Smith, G. D.: Ozonolysis of oleic acid particles: evidence for a surface reaction and secondary reactions involving Criegee intermediates, Phys. Chem. Chem. Phys., 7, 501-511, doi:10.1039/B414472d, 2005.

Hoffer, A., Kiss, G., Blazso, M., and Gelencser, A.: Chemical characterization of humic-like substances (HULIS) formed from a lignin-type precursor in model cloud water, Geophys. Res. Lett., 31, L06115, doi:10.1029/2003g1018962, 2004.

Hoffer, A., Gelencsér, A., Blazsó, M., Guyon, P., Artaxo, P., and Andreae, M. O.: Diel and seasonal variations in the chemical composition of biomass burning aerosol, Atmos. Chem. Phys., 6, 3505-3515, doi:10.5194/acp-6-3505-2006, 2006.

Irikura, K. K., Johnson, R. D., and Kacker, R. N.: Uncertainties in scaling factors for ab initio vibrational frequencies, J. Phys. Chem. A, 109, 8430-8437, doi:10.1021/Jp052793n, 2005.

Jang, M., Czoschke, N. M., Lee, S., and Kamens, R. M.: Heterogeneous atmospheric aerosol production by acid-catalyzed particlephase reations, Science, 298, 814-817, 2002.

Janhäll, S., Andreae, M. O., and Pöschl, U.: Biomass burning aerosol emissions from vegetation fires: particle number and mass emission factors and size distributions, Atmos. Chem. Phys., 10, 1427-1439, doi:10.5194/acp-10-1427-2010, 2010.

Kasischke, E. S. and Penner, J. E.: Improving global estimates of atmospheric emissions from biomass burning, J. Geophys. Res.Atmos., 109, D14S01, doi:10.1029/2004jd004972, 2004.

Kiehl, J. T. and Rodhe, H.: Modeling geographical and seasonal forcing due to aerosols, in: Aerosol Forcing of Climate, Wiley, New York, 281-296, 1995.

Kjallstrand, J., Ramnas, O., and Petersson, G.: Gas chromatographic and mass spectrometric analysis of 36 ligninrelated methoxyphenols from uncontrolled combustion of wood, J. Chromatogr. A, 824, 205-210, doi:10.1016/S00219673(98)00698-0, 1998.

Knopf, D. A., Forrester, S. M., and Slade, J. H.: Heterogeneous oxidation kinetics of organic biomass burning aerosol surrogates by $\mathrm{O}_{3}, \mathrm{NO}_{2}, \mathrm{~N}_{2} \mathrm{O}_{5}$, and $\mathrm{NO}_{3}$, Phys. Chem. Chem. Phys., 13, 21050-21062, doi:10.1039/C1cp22478f, 2011.
Kwamena, N. O. A., Thornton, J. A., and Abbatt, J. P. D.: Kinetics of surface-bound benzo[a]pyrene and ozone on solid organic and salt aerosols, J. Phys. Chem. A, 108, 11626-11634, doi:10.1021/Jp046161x, 2004.

Kwamena, N. O. A., Staikova, M. G., Donaldson, D. J., George, I. J., and Abbatt, J. P. D.: Role of the aerosol substrate in the heterogeneous ozonation reactions of surface-bound PAHs, J. Phys. Chem. A, 111, 11050-11058, doi:10.1021/Jp075300i, 2007.

Li, J., Posfai, M., Hobbs, P. V., and Buseck, P. R.: Individual aerosol particles from biomass burning in southern Africa: 2, Compositions and aging of inorganic particles, J. Geophys. Res.-Atmos., 108, 8484, doi:10.1029/2002jd002310, 2003.

Li, W. J., Shao, L. Y., and Buseck, P. R.: Haze types in Beijing and the influence of agricultural biomass burning, Atmos. Chem. Phys., 10, 8119-8130, doi:10.5194/acp-10-8119-2010, 2010.

Liu, C. G., Zhang, P., Wang, Y. F., Yang, B., and Shu, J. N.: Heterogeneous reactions of particulate methoxyphenols with $\mathrm{NO}_{3}$ radicals: kinetics, products, and mechanisms, Environ. Sci. Technol., 46, 13262-13269, doi:10.1021/Es303889z, 2012.

Lu, J. W., Fiegland, L. R., Davis, E. D., Alexander, W. A., Wagner, A., Gandour, R. D., and Morris, J. R.: Initial reaction probability and dynamics of ozone collisions with a vinyl-terminated self-assembled monolayer, J. Phys. Chem. C, 115, 25343-25350, doi:10.1021/Jp2079692, 2011.

Moise, T. and Rudich, Y.: Reactive uptake of ozone by aerosol-associated unsaturated fatty acids: kinetics, mechanism, and products, J. Phys. Chem. A, 106, 6469-6476, doi:10.1021/Jp025597e, 2002.

Morris, J. W., Davidovits, P., Jayne, J. T., Jimenez, J. L., Shi, Q., Kolb, C. E., Worsnop, D. R., Barney, W. S., and Cass, G.: Kinetics of submicron oleic acid aerosols with ozone: a novel aerosol mass spectrometric technique, Geophys. Res. Lett., 29, 71-1-714, doi:10.1029/2002gl014692, 2002.

Net, S., Alvarez, E. G., Balzer, N., Wortham, H., Zetzsch, C., and Gligorovski, S.: Photolysis and heterogeneous reaction of coniferyl aldehyde adsorbed on silica particles with ozone, ChemPhysChem, 11, 4019-4027, doi:10.1002/cphc.201000446, 2010a.

Net, S., Gligorovski, S., Pietri, S., and Wortham, H.: Photoenhanced degradation of veratraldehyde upon the heterogeneous ozone reactions, Phys. Chem. Chem. Phys., 12, 7603-7611, doi:10.1039/B922957d, 2010b.

Net, S., Gligorovski, S., and Wortham, H.: Light-induced heterogeneous ozone processing on organic coated particles: kinetics and condensed-phase products, Atmos. Environ., 44, 3286-3294, doi:10.1016/j.atmosenv.2010.05.050, 2010c.

Net, S., Alvarez, E. G., Gligorovski, S., and Wortham, H.: Heterogeneous reactions of ozone with methoxyphenols, in presence and absence of light, Atmos. Environ., 45, 3007-3014, doi:10.1016/j.atmosenv.2011.03.026, 2011.

Nolte, C. G., Schauer, J. J., Cass, G. R., and Simoneit, B. R. T.: Highly polar organic compounds present in wood smoke and in the ambient atmosphere, Environ. Sci. Technol., 35, 1912-1919, doi:10.1021/Es001420r, 2001.

Ofner, J., Kruger, H. U., and Zetzsch, C.: Time resolved infrared spectroscopy of formation and processing of secondary organic aerosol, Z. Phys. Chem., 224, 1171-1183, doi:10.1524/zpch.2010.6146, 2010. 
Ofner, J., Krüger, H.-U., Grothe, H., Schmitt-Kopplin, P., Whitmore, K., and Zetzsch, C.: Physico-chemical characterization of SOA derived from catechol and guaiacol - a model substance for the aromatic fraction of atmospheric HULIS, Atmos. Chem. Phys., 11, 1-15, doi:10.5194/acp-11-1-2011, 2011.

Oros, D. R. and Simoneit, B. R. T.: Identification and emission factors of molecular tracers in organic aerosols from biomass burning Part 1. Temperate climate conifers, Appl. Geochem., 16, 1513-1544, 2001a.

Oros, D. R. and Simoneit, B. R. T.: Identification and emission factors of molecular tracers in organic aerosols from biomass burning Part 2. Deciduous trees, Appl. Geochem., 16, 1545-1565, 2001b.

Pflieger, M., Monod, A., and Wortham, H.: Kinetic study of heterogeneous ozonolysis of alachlor, trifluralin and terbuthylazine adsorbed on silica particles under atmospheric conditions, Atmos. Environ., 43, 5597-5603, doi:10.1016/j.atmosenv.2009.07.064, 2009.

Posfai, M., Simonics, R., Li, J., Hobbs, P. V., and Buseck, P. R.: Individual aerosol particles from biomass burning in southern Africa: 1. Compositions and size distributions of carbonaceous particles, J. Geophys. Res.-Atmos., 108, 8483, doi:10.1029/2002jd002291, 2003.

Reid, J. S., Koppmann, R., Eck, T. F., and Eleuterio, D. P.: A review of biomass burning emissions part II: intensive physical properties of biomass burning particles, Atmos. Chem. Phys., 5, 799825, doi:10.5194/acp-5-799-2005, 2005.

Rosen, E. P., Garland, E. R., and Baer, T.: Ozonolysis of oleic acid adsorbed to polar and nonpolar aerosol particles, J. Phys. Chem. A, 112, 10315-10324, doi:10.1021/Jp8045802, 2008.

Sachdev, S. L., Lodge Jr., J. P., and West, P. W.: Specific method for the determination of ozone in the atmosphere, Anal. Chim. Acta, 58, 141-147, doi:10.1016/S0003-2670(00)86863-4, 1972.

Schauer, J. J., Kleeman, M. J., Cass, G. R., and Simoneit, B. R. T.: Measurement of emissions from air pollution sources. 3. C-1C-29 organic compounds from fireplace combustion of wood, Environ. Sci. Technol., 35, 1716-1728, doi:10.1021/Es001331e, 2001.
Seiler, W. and Crutzen, P.: Estimates of gross and net fluxes of carbon between the biosphere and the atmosphere from biomass burning, Climatic Change, 2, 207-247, doi:10.1007/bf00137988, 1980.

Shakya, K. M., Louchouarn, P., and Griffin, R. J.: Ligninderived phenols in Houston aerosols: implications for natural background sources, Environ. Sci. Technol., 45, 8268-8275, doi:10.1021/Es201668y, 2011.

Socrates, G.: Infrared and Raman Characteristic Group Frequencies, 3rd edn., John Wiley \& Sons, Chichester, 2001.

Sullivan, R. C., Thornberry, T., and Abbatt, J. P. D.: Ozone decomposition kinetics on alumina: effects of ozone partial pressure, relative humidity and repeated oxidation cycles, Atmos. Chem. Phys., 4, 1301-1310, doi:10.5194/acp-4-1301-2004, 2004.

Thornberry, T. and Abbatt, J. P. D.: Heterogeneous reaction of ozone with liquid unsaturated fatty acids: detailed kinetics and gas-phase product studies, Phys. Chem. Chem. Phys., 6, 84-93, doi:10.1039/B310149e, 2004.

Vingarzan, R.: A review of surface ozone background levels and trends, Atmos. Environ., 38, 3431-3442, doi:10.1016/j.atmosenv.2004.03.030, 2004.

Woodill, L. A., O’Neill, E. M., and Hinrichs, R. Z.: Impacts of surface adsorbed catechol on tropospheric aerosol surrogates: heterogeneous ozonolysis and its effects on water uptake, J. Phys. Chem. A, 117, 5620-5631, doi:10.1021/jp400748r, 2013.

Wool, R. and Sun, X. S.: Bio-Based Polymers and Composites, Academic Press, Burlington, MA, 1-14, 2005.

Zhang, Y., Obrist, D., Zielinska, B., and Gertler, A.: Particulate emissions from different types of biomass burning, Atmos. Environ., 72, 27-35, 2013.

Zhou, S., Lee, A. K. Y., McWhinney, R. D., and Abbatt, J. P. D.: Burial effects of organic coatings on the heterogeneous reactivity of particle-borne benzo[a]pyrene (BaP) toward ozone, J. Phys. Chem. A, 116, 7050-7056, doi:10.1021/Jp3030705, 2012. 